\title{
COU254, a specific 3-carboxamide-coumarin inhibitor of coagulation factor XII, does not protect mice from acute ischemic stroke
}

\author{
Peter Kraft' ${ }^{1}$, Tobias Schwarz ${ }^{1}$, Lionel Pochet ${ }^{2}$, Guido Stoll1 ${ }^{1}$, Christoph Kleinschnitz ${ }^{1 *}$
}

\begin{abstract}
Background: Anticoagulation is an important means to prevent from acute ischemic stroke but is associated with a significant risk of severe hemorrhages. Previous studies have shown that blood coagulation factor XII (FXII)deficient mice are protected from pathological thrombus formation during cerebral ischemia without bearing an increased bleeding tendency. Hence, pharmacological blockade of FXII might be a promising and safe approach to prevent acute ischemic stroke and possibly other thromboembolic disorders but pharmacological inhibitors selective over FXII are still lacking. In the present study we investigated the efficacy of COU254, a novel nonpeptidic 3-carboxamide-coumarin that selectively blocks FXII activity, on stroke development and post stroke functional outcome in mice.
\end{abstract}

Methods: C57Bl/6 mice were treated with COU254 (40 mg/kg i.p.) or vehicle and subjected to 60 min transient middle cerebral artery occlusion (tMCAO) using the intraluminal filament method. After $24 \mathrm{~h}$ infarct volumes were determined from 2,3,5-Triphenyltetrazoliumchloride(TTC)-stained brain sections and functional scores were assessed. Hematoxylin and eosin (H\&E) staining was used to estimate the extent of neuronal cell damage. Thrombus formation within the infarcted brain areas was analyzed by immunoblot.

Results: Infarct volumes and functional outcomes on day 1 after tMCAO did not significantly differ between COU254 pre-treated mice or untreated controls $(p>0.05$ ). Histology revealed extensive ischemic neuronal damage regularly including the cortex and the basal ganglia in both groups. COU254 treatment did not prevent intracerebral fibrin(ogen) formation.

Conclusions: COU254 at the given concentration of $40 \mathrm{mg} / \mathrm{kg}$ failed to demonstrate efficacy in acute ischemic stroke in this preliminary study. Further preclinical evaluation of 3-carboxamide-coumarins is needed before the antithrombotic potential of this novel class of FXII inhibitors can be finally judged.

\section{Introduction}

Thromboembolic occlusion of intracerebral vessels is responsible for the majority of ischemic strokes [1]. Studies on the early use of anticoagulant drugs (e.g. heparin) in cerebral ischemia failed to demonstrate overall benefit in that reduced lesion progression was counterbalanced by an increase in hemorrhages [2]. In addition, long-term anticoagulation for secondary prevention of cardioembolic stroke, mainly accomplished by warfarin prescription, is inevitably associated with

\footnotetext{
* Correspondence: christoph.kleinschnitz@mail.uni-wuerzburg.de 'Department of Neurology, Josef-Schneider-Str. 11, University Clinic of Wuerzburg, Germany
}

C 2010 Kraft et al; licensee BioMed Central Ltd. This is an Open Access article distributed under the terms of the Creative Commons Attribution License (http://creativecommons.org/licenses/by/2.0), which permits unrestricted use, distribution, and reproduction in any medium, provided the original work is properly cited. and safer anticoagulation in patients with imminent stroke is badly needed.

In the classical "waterfall model" of blood coagulation the formation of a fibrin thrombus can be initiated by two distinct pathways, the extrinsic and the intrinsic pathway [4]. Both cascades consist of a series of proteolytic reactions involving trypsin-like serine proteases [5]. Fibrin formation via the extrinsic pathway occurs when tissue factor (TF), located on cell membranes in the subendothelium of a vessel, forms a complex with activated coagulation factor VII (FVIIa) after endothelial injury [6]. According to the original assumption, the 
intrinsic pathway is initiated when coagulation factor XII (FXII) becomes activated on a negatively charged surface followed by successive activation of factor XI (FXI) and factor IX (FIX) [7]. FXII has long been considered to be dispensable for clot formation because humans with hereditary FXII deficiency suffer from neither spontaneous nor injury-related abnormal bleedings $[8,9]$. This concept was recently called into question by studies demonstrating that FXII-deficient mice are profoundly protected from pathological thrombus formation in different models of arterial thrombosis but, like FXII-deficient humans, do not show impaired hemostasis $[10,11]$. Consequently, it was anticipated that the use of FXII inhibitors would be associated with relatively low rates of therapy-related hemorrhages, the major clinical complication associated with current anticoagulant therapies [1]. Indeed, wild-type mice treated with D-Pro-Phe-Arg chloromethyl ketone (PCK), which blocks the amidolytic activity of FXIIa, and subjected to ischemic stroke afterwards, developed less vessel occlusive thrombi in the cerebral microvasculature but did not show increased bleeding tendencies [11]. However, PCK is not selective over FXII and also interacts with other components of the plasmatic coagulation cascade [12].

Pochet and co-workers recently described the synthesis of new 3-carboxamide-coumarins which are the first selective nonpeptidic inhibitors of FXIIa [12]. COU254 is a member of this novel class of FXII inhibitors. In the present study we assessed the effect of COU254 on stroke development, intracerebral fibrinogen clotting and post stroke functional outcome in mice.

\section{Methods}

\section{Animal experiments}

A total of 26 mice were used in this study. Animal experiments were approved by legal state authorities (Bezirksregierung of Unterfranken) and conducted according to the recommendations for research in basic stroke studies [13]. Focal cerebral ischemia was induced in 6-8-weeks old male C57Bl/6 mice (Harlan Winkelmann, Borchen, Germany) by 60 min transient middle cerebral artery occlusion (tMCAO) as described $[11,14]$. Mice were anesthetized with 2.5\% isoflurane (Abbott, Wiesbaden, Germany). Following a midline skin incision in the neck, the proximal common carotid artery and the external carotid artery were ligated and a standardized silicon rubber-coated 6.0 nylon monofilament (6021; Doccol Corp., Redlands, CA, USA) was inserted and advanced via the right internal carotid artery to occlude the origin of the right MCA. The operator was blinded to the treatment groups and operation time per animal did not exceed 15 minutes. The intraluminal suture was left in situ for 60 minutes. Then animals were re-anesthetized and the occluding monofilament was withdrawn to allow reperfusion.

COU254 dissolved in 25\% DMSO was administered intraperitoneally (i.p.) $2 \mathrm{~h}$ before the induction of tMCAO at a dosage of $40 \mathrm{mg} / \mathrm{kg}$ bodyweight. Vehicletreated control mice receiving 25\% DMSO without COU254 served as controls. The i.p. route of administration was chosen because i.v. application was afflicted with significant acute toxicity and mortality in preliminary experiments.

\section{Determination of infarct size and histology}

Edema-corrected infarct volumes were quantified by planimetry from 2,3,5-Triphenyltetrazoliumchloride (TTC)stained brain sections $24 \mathrm{~h}$ after ischemic stroke as described $[11,14,15]$. For morphological assessment, paraffin embedded brains were stained with hematoxylin and eosin $(\mathrm{H} \& \mathrm{E})$.

\section{Protein extraction and Western blot analysis}

Following TTC staining cortices were dissected from formalin-fixed brain slices and homogenized in RIPA buffer (25 mM Tris pH 7.4, $150 \mathrm{mM} \mathrm{NaCl}, 1 \% \mathrm{NP} 40$ ) containing $2 \%$ SDS. The samples were incubated for 20 min at $100^{\circ} \mathrm{C}$ followed by incubation at $60^{\circ} \mathrm{C}$ for $2 \mathrm{~h}$ [16]. After that, tissue lysates were centrifuged at 15.000 $\times \mathrm{g}$ for $20 \mathrm{~min}$ at $4^{\circ} \mathrm{C}$ and supernatants were used for $\mathrm{BCA}$ protein assay and subsequent Western blot analysis.

The total lysates were treated with SDS-PAGE loading buffer (final conc. $65 \mathrm{mM}$ Tris, 5\% 2-mercaptoethanol, $3 \% \mathrm{SDS}, 10 \%$ glycerol) at $95^{\circ} \mathrm{C}$ for $5 \mathrm{~min} .30 \mu \mathrm{g}$ of total protein were electrophoresed and transferred to a PVDF membrane. After blocking for $1 \mathrm{~h}$ with blocking buffer (5\% nonfat dry milk, $50 \mathrm{mM}$ Tris- $\mathrm{HCl} \mathrm{pH} 7.5,150 \mathrm{mM}$ $\mathrm{NaCl}, 0.05 \%$ Tween-20) membranes were incubated with the primary antibody at $4{ }^{\circ} \mathrm{C}$ over night at the following dilutions: anti-Fibrinogen (cross-reactive against fibrin) pAb 1:500 (Acris Antibodies) and anti-Actin mAb 1:10,000 (Dianova). After a washing step with TBS-T (50 mM Tris-HCl pH 7.5, $150 \mathrm{mM} \mathrm{NaCl}, 0.05 \%$ Tween-20), membranes were incubated for $1 \mathrm{~h}$ with HRP-conjugated donkey anti-rabbit IgG (for Fibrinogen) or donkey anti-mouse IgG (for Actin) at a dilution of 1:5000 and were finally developed using ECLplus (GE Healthcare).

\section{Assessment of functional outcome}

24 $\mathrm{h}$ after tMCAO the modified Bederson score [17] was used to determine global neurological function according to the following scoring system: 0 , no deficit; 1 , forelimb flexion; 2, decreased resistance to lateral push; 3 , unidirectional circling; 4, longitudinal spinning; 5 , no movement. Motor function and coordination were 


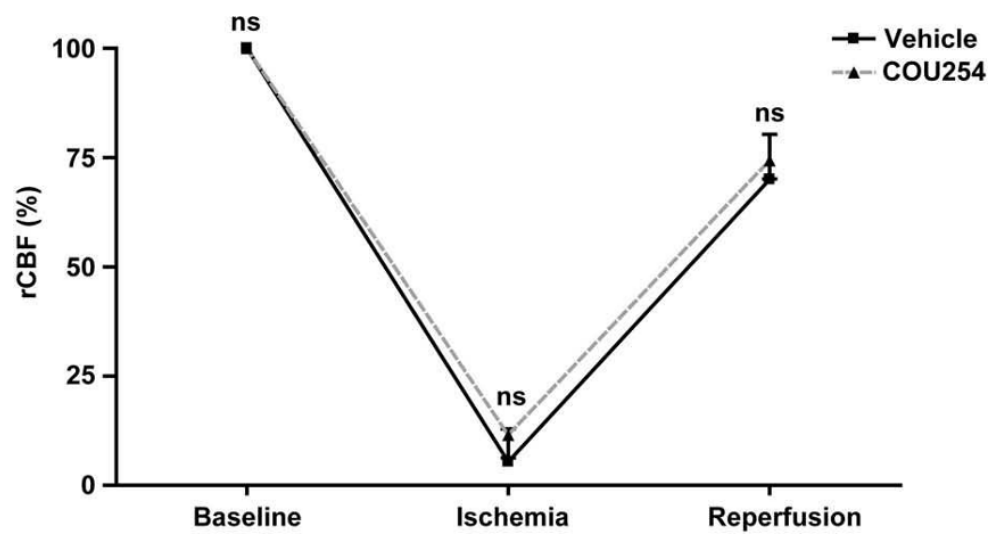

Figure 1 rCBF does not differ between COU254-treated mice and controls after tMCAO. Determination of regional cerebral blood flow (rCBF) using Laser Doppler flowmetry before the occlusion of the middle cerebral artery (baseline), 10 min after the occlusion (ischemia) and again $10 \mathrm{~min}$ after the removal of the filament (reperfusion) in COU254-treated mice and vehicle-treated controls $(\mathrm{n}=3 / \mathrm{group}$ ). No significant differences in rCBF were observed between the two groups. 1-way ANOVA, Bonferroni post hoc test, ns = not significant.

evaluated by the grip test [18]. For this test, the mouse was placed midway on a string between two supports and rated as follows: 0 , falls off; 1 , hangs onto string by one or both forepaws; 2 , as for 1 , and attempts to climb onto string; 3 , hangs onto string by one or both forepaws plus one or both hindpaws; 4 , hangs onto string by fore- and hindpaws plus tail wrapped around string; 5 , escape (to the supports). Neurological scores were always assessed by an independent and blinded investigator.

\section{Laser-Doppler flowmetry}

Laser-Doppler flowmetry (Moor Instruments, Axminster, U.K.) was used in some animals ( $n=3$ /group) to monitor regional cerebral blood flow ( $\mathrm{rCBF}$ ) in the MCA territory $(6 \mathrm{~mm}$ lateral and $2 \mathrm{~mm}$ posterior from bregma) [19].

\section{Statistics}

Data are expressed as mean \pm standard deviation (SD). For statistical analysis, PrismGraph 4.0 software package (La Jolla, CA, USA) was used. Infarct volumes and neurological scores were analyzed using the non-parametric Mann Whitney test. Laser Doppler flowmetry data were compared by 1-way ANOVA followed by Bonferroni post hoc test. P-values $<0.05$ were considered to be statistically significant.

\section{Results}

The transient middle cerebral artery filament occlusion model (tMCAO) was used to induce focal cerebral ischemia in mice $[11,14,15]$. After advancing the filament to the origin of the MCA the decrease in $\mathrm{rCBF}$ was similar between control mice and COU254-treated mice $(5.4 \pm 7.5 \%$ of baseline levels vs. $11.5 \pm 5.2 \%$ of baseline levels; $\mathrm{p}>0.05$ ) (Figure 1). Ten minutes after reperfusion $\mathrm{rCBF}$ in the MCA territory was reconstituted to $>70 \%$ of baseline levels and again did not significantly differ between treated and untreated mice (70.0 $\pm 10.3 \%$ of baseline levels vs. $74.3 \pm 4.2 \%$ of baseline levels; $\mathrm{p}>0.05$ ) (Figure 1). Taken together, these findings exclude any significant $\mathrm{rCBF}$ alterations related to COU254 or vehicle treatment and prove that MCA occlusion and reperfusion were sufficient in our model.

As a next step, we determined infarct sizes and the extent of neuronal damage in control mice and mice treated with COU254. 24 h after tMCAO no significant differences in infarct volumes were observed between the two groups as revealed by 2,3,5-Triphenyltetrazoliumchloride (TTC) staining and successive infarct planimetry $\left(101.5 \pm 31.4 \mathrm{~mm}^{3}\right.$ vs. $110.0 \pm 27.2 \mathrm{~mm}^{3} ; \mathrm{p}>$ 0.05) (Figure 2a). In line with these findings, $H \& E$ staining confirmed widespread ischemic neurodegeneration in both groups which regularly expanded to the basal ganglia and the neocortex (Figure 2a). Detailed analysis of the neurological status using two different functional scores also could not reveal any beneficial effects of COU254 in acute ischemic stroke (Bederson score: $2.8 \pm$ 1.4 vs. $2.4 \pm 1.8$; $\mathrm{p}>0.05$; grip test: $2.0 \pm 1.4$ vs. $2.5 \pm$ $1.9 ; \mathrm{p}>0.05$ ) (Figure 2b). Finally, no differences in thrombus formation within the infarcted brain areas of COU254-treated mice or controls were detectable by immunoblot (Figure 2c).

\section{Discussion}

Unexpectedly, the selective nonpeptidic FXIIa inhibitor COU254 could not ameliorate ischemic brain damage after $\mathrm{tMCAO}$ in mice.

COU254 belongs to a new group of recently described 3-carboxamide-coumarins which represent the first 


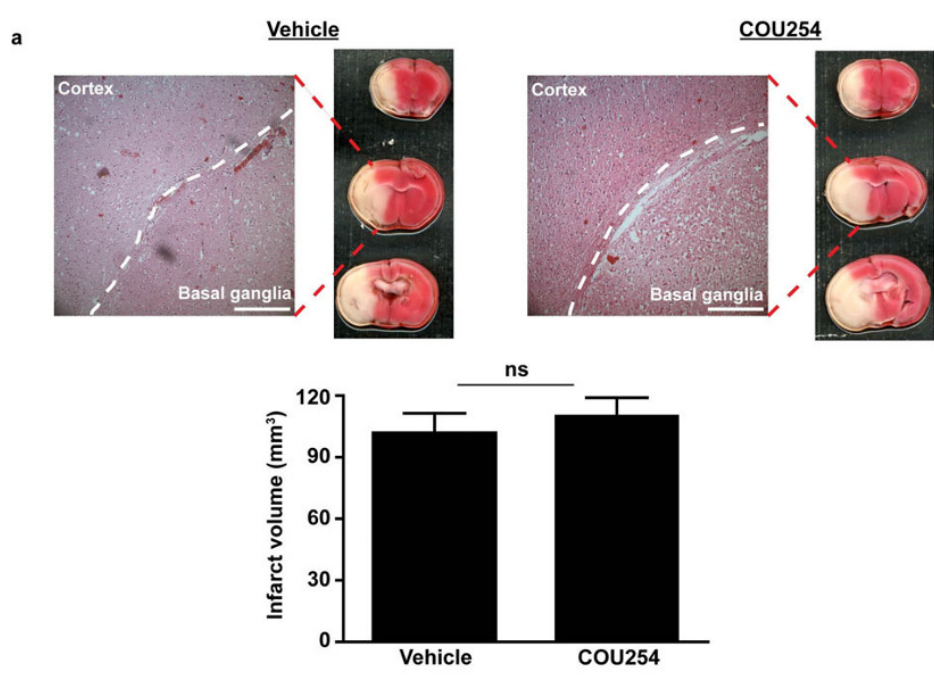

b
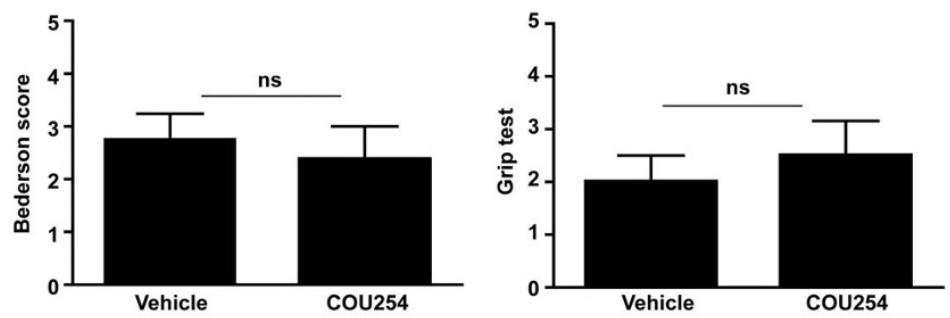

c

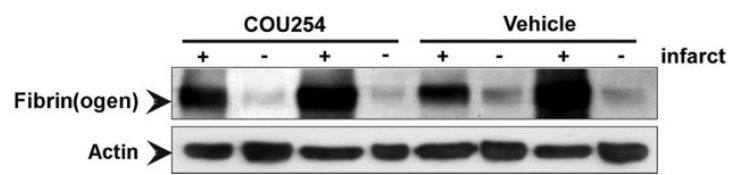

Figure 2 COU254 does not improve outcome after experimental stroke in mice. Infarct size and functional outcome in COU254-treated mice and controls (vehicle) $24 \mathrm{~h}$ after $60 \mathrm{~min}$ transient middle cerebral artery occlusion (tMCAO). (a) (top) Representative 2,3,5-

Triphenyltetrazoliumchloride (TTC)-stained coronal brain sections from the two animal groups. Ischemic infarctions appear white and regularly include the neocortex and basal ganglia as confirmed by hematoxylin and eosin (H\&E) staining (bar represents $250 \mu \mathrm{m}$ ). (bottom) Infarct volumes on day 1 after TMCAO in COU254-treated mice and vehicle-treated controls as determined by planimetry ( $\mathrm{n}=10 / \mathrm{group})$. Nonparametric Mann Whitney test, ns = not significant. (b) Neurological Bederson score and grip test score on day 1 after tMCAO in COU254treated mice and vehicle-treated controls. In line with the results on infarct volumes, no significant functional differences became apparent between the treatment groups. Non-parametric Mann Whitney test, ns = not significant. (c) Accumulation of fibrin(ogen) in the infarcted (+) and contralateral (-) cortices of COU254-treated mice or vehicle-treated controls. Fibrinogen clotting $24 \mathrm{~h}$ after ischemia was analyzed by immunoblotting. Two representative immunoblots of each group are shown.

selective inhibitors of FXIIa [12]. In contrast to conventional FXII inhibitors it does not interfere with other components of the contact activation system or plasmatic coagulation cascade potentially involved in stroke development such as kallikrein, FXa or the TF/FVIIa complex [15]. Mechanistically, COU254 mediates antiFXII activity through the formation of an acyl enzyme instead of an alkyl enzyme as observed with thrombin and 6-chloromethyl ester coumarins [12]. Several reports have meanwhile highlighted the role of FXII in pathological thrombogenesis [20]. FXII-deficient mice were protected against arterial thrombosis, collageninduced venous thromboembolism and ischemic stroke [10,11]. Importantly, FXII ${ }^{-/}$mice display normal hemostasis and consequently FXIIa inhibition was not associated with increased bleeding complications supporting the intriguing hypothesis that hemostasis and thrombosis are two mechanistically different processes [20]. Hence, FXIIa is considered an attractive target for pharmacological inhibitors designed to treat or prevent thromboembolic disorders. Such a safe therapy might be particularly advantageous for the treatment of acute 
ischemic stroke, where the conventional anticoagulants used against stroke progression or recurrence are inheritably associated with increased bleeding-related morbidity and mortality [1].

We recently established D-Pro-Phe-Arg chloromethyl ketone (PCK) as FXIIa inhibitor in experimental stroke [11]. Mice treated with PCK immediately before the occlusion of the middle cerebral artery (MCA) developed smaller infarcts and less severe neurological deficits compared to controls. Moreover, the formation of fibrin within the infarcted brains was significantly reduced. Although PCK irreversibly inhibits the amidolytic activity of FXIIa it is not specific over FXII. Rather, PCK has been shown to block other components of the contact activation system or plasmatic coagulation cascade bearing the potential risk of undesired adverse effects [12]. Moreover, the peptidic structure and the alkylating behavior of the chloromethyl function prevent the application of PCK as oral anticoagulant. Natural anticoagulant proteins displaying anti-FXIIa activity were also reported, e.g. from leguminous plants [21], hematophagous insects [22-24], helminth parasites [25] and bacteria [26]. Again, despite their proven efficacy, all these proteins were generally not selective over blood coagulation proteases.

Several reasons might account for the negative results in present study. Besides "true" inefficacy of COU254 in acute experimental stroke related for example to the relatively low FXIIa inhibitory potency of COU254 compared to PCK [12] technical limitations could have been responsible. The anti-FXIIa activity of COU254 has only been established from in vitro dose-response curves so far and pharmacodynamic or pharmacokinetic data on COU254 in animals, especially rodents, are lacking. Moreover, the optimum dosage or route of application of COU254 in mice is yet unknown as is the ideal time point of administration during the course of ischemic stroke. Because human and mouse FXII share a high degree of sequence homology and the established human FXII inhibitors usually also block murine FXII $[10,11]$, species specific differences of COU254 mode of action between humans and rodents seem unlikely but cannot be completely ruled out.

In summary, 3-carboxamide-coumarins represent a promising new class of selective FXII inhibitors but further preclinical evaluation of these compounds in animal models is clearly needed before any firm conclusions on their antithrombotic potential can be drawn.

\section{Acknowledgements}

The expert technical assistance of Melanie Glaser and Daniela Urlaub is highly appreciated. This work was supported by the Deutsche Forschungsgemeinschaft (SFB 688 TP B1 and A13).

\section{Author details}

${ }^{1}$ Department of Neurology, Josef-Schneider-Str. 11, University Clinic of Wuerzburg, Germany. ${ }^{2}$ Department of Pharmacy, Drug Design and Discovery Center, FUNDP, University of Namur, Belgium.

\section{Authors' contributions}

All authors have read and approved the final manuscript.

PK operated the animals, assessed the functional scores and interpreted the data. TS performed the immunoblots. LP provided COU254 and finalized the manuscript. GS and CK conceived the experiments, funded the project and wrote the manuscript.

\section{Competing interests}

The authors declare that they have no competing interests.

Received: 8 January 2010

Accepted: 15 February 2010 Published: 15 February 2010

\section{References}

1. Stoll G, Kleinschnitz C, Nieswandt B: Molecular mechanisms of thrombus formation in ischemic stroke: novel insights and targets fortreatment. Blood 2008, 112:3555-3562.

2. Sandercock PA, Counsell C, Kamal A: Anticoagulants for acute ischaemic stroke. Cochrane Database of Systematic Reviews 2008, , 4: CD000024.

3. Levine MN, Raskob G, Landefeld S, Kearon C: Hemorrhagic complications of anticoagulant treatment. Chest 2001, 119(Suppl 1):108S-121S.

4. Davie EW, Ratnoff OD: Waterfall sequence for intrinsic blood clotting. Science 1964, 145:1310-1312.

5. Macfarlane RG: An enzyme cascade in the blood clotting mechanism, and its function as a biochemical amplifier. Nature 1964, 202:498-499.

6. Mackman N: Role of tissue factor in hemostasis, thrombosis, and vascular development. Arterioscler Thromb Vasc Biol 2004, 24:1015-1022.

7. Gailani D, Renné T: Intrinsic pathway of coagulation and arterial thrombosis. Arterioscler Thromb Vasc Biol 2007, 27:2507-2513.

8. Ratnoff OD, Colopy JE: A familial hemorrhagic trait associated with a deficiency of a clot-promoting fraction of plasma. J Clin Invest 1955, 34:602-613.

9. Gailani D, Broze GJ Jr: Factor XI activation in a revised model of blood coagulation. Science 1991, 253:909-912.

10. Renne T, Pozgajova M, Gruner S, Schuh K, Pauer HU, Burfeind P, Gailani D, Nieswandt B: Defective thrombus formation in mice lacking coagulation factor XII. J Exp Med 2005, 202:271-281.

11. Kleinschnitz C, Stoll G, Bendszus M, Schuh K, Pauer HU, Burfeind P, Renné $C$, Gailani D, Nieswandt B, Renné T: Targeting coagulation factor XII provides protection from pathological thrombosis in cerebral ischemia without interfering with hemostasis. J Exp Med 2006, 203:513-518.

12. Robert S, Bertolla C, Masereel B, Dogné JM, Pochet L: Novel 3Carboxamide-coumarins as Potent and Selective FXIla Inhibitors. J Med Chem 2008, 51:3077-3080.

13. Dirnagl U: Bench to bedside: the quest for quality in experimental stroke research. J Cereb Blood Flow Metab 2006, 26:1465-78.

14. Berna-Erro A, Braun A, Kraft R, Kleinschnitz C, Schuhmann MK, Stegner D, Wultsch T, Eilers J, Meuth SG, Stoll G, Nieswandt B: STIM2 regulates capacitive $\mathrm{Ca} 2+$ entry in neurons and plays a key role in hypoxic neuronal cell death. Sci Signal 2009, 2:ra67.

15. Austinat $M$, Braeuninger $S$, Pesquero JB, Brede $M$, Bader $M$, Stoll $G$, Renné $T$, Kleinschnitz C: Blockade of bradykinin receptor B1 but not bradykinin receptor B2 provides protection from cerebral infarction and brain edema. Stroke 2009, 40:285-93.

16. Ikeda K, Monden T, Kanoh T, Tsujie M, Izawa H, Haba A, Ohnishi T, Sekimoto M, Tomita N, Shiozaki H, Monden M: Extraction and analysis of diagnostically useful proteins from formalin-fixed, paraffin-embedded tissue sections. J Histochem Cytochem 1998, 46:397-403.

17. Bederson JB, Pitts LH, Tsuji M, Nishimura MC, Davis RL, Bartkowski $H$ : evaluation of the model and development of a neurologic examination. Stroke 1986, 17:472-476.

18. Moran PM, Higgins LS, Cordell B, Moser PC: Age-related learning deficits in transgenic mice expressing the 751-amino acid isoform of human amyloid precursor protein. Proc Natl Acad Sci 1995, 92:5341-5345. 
19. Connolly ES Jr, Winfree CJ, Stern DM, Solomon RA, Pinsky DJ: Procedural and strain-related variables significantly affect outcome in a murine model of focal cerebral ischemia. Neurosurgery 1996, 38:523-532.

20. Gailani D, Renné $T$ : The intrinsic pathway of coagulation:a target for treating thromboembolic disease?. J Thromb Haemost 2007, 5:1106-12.

21. Carter TH, Everson BA, Ratnoff OD: Cabbage seed protease inhibitor: a slow, tight-binding inhibitor of trypsin with activity toward thrombin activated Stuart factor (factor Xa), activated Hageman factor (factor XIla), and plasmin. Blood 1990, 75:108-115.

22. Campos IT, Tanaka-Azevedo AM, Tanaka AS: Identification and characterization of a novel factor XIla inhibitor in the hematophagous insect, Triatoma infestans (Hemiptera: Reduviidae). FEBS Lett 2004, 577:512-516.

23. Isawa H, Orito Y, Jingushi N, Iwanaga S, Morita A, Chinzei Y, Yuda M: Identification and characterization of plasma kallikrein-kinin system inhibitors from salivary glands of the blood-sucking insect Triatoma infestans. FEBS J 2007, 274:4271-86.

24. Decrem $Y$, Rath $G$, Blasioli V, Cauchie $P$, Robert $S$, Beaufays J, Frère JM, Feron O, Dogné JM, Dessy C, Vanhamme L, Godfroid E: Ir-CPI, a coagulation contact phase inhibitor from the tick Ixodes ricinus, inhibits thrombus formation without impairing hemostasis. J Exp Med 2009, 206:2381-95.

25. Foster CB, Flanigan TP, DeStigter KK, Blanton R, Dumenco LL, Gallagher C, Ratnoff OD: Inhibition of the activation of Hageman factor (factor XII) by extracts of Schistosoma mansoni. J Lab Clin Med 1992, 120:735-739.

26. Ulmer JS, Lindquist RN, Dennis MS, Lazarus RA: Ecotin is a potent inhibitor of the contact system proteases factor XIla and plasma kallikrein. FEBS Lett 1995, 365:159-163.

doi:10.1186/2040-7378-2-5

Cite this article as: Kraft et al: COU254, a specific 3-carboxamidecoumarin inhibitor of coagulation factor XII, does not protect mice from acute ischemic stroke. Experimental \& Translational Stroke Medicine 2010 2:5.

\section{Submit your next manuscript to BioMed Central and take full advantage of:}

- Convenient online submission

- Thorough peer review

- No space constraints or color figure charges

- Immediate publication on acceptance

- Inclusion in PubMed, CAS, Scopus and Google Scholar

- Research which is freely available for redistribution

Submit your manuscript at www.biomedcentral.com/submit 